\title{
Detection of Training Needs of Workers in the Fur Industry: The case of Macedonia Greece
}

\author{
Vasiliki Brinia (Corresponding Author) \\ Teacher Education Program \\ Athens University of Economics \& Business \\ E-mail: vbrinia@aueb.gr \\ Harilaos Vanidis \\ Hellenic Open University \\ E-mail: vanidisx@gmail.com
}

Received: February 24, 2018

doi:10.5296/jet.v5i2.13021
Accepted: March 24, 2018

Published: April 18, 2018

URL: http://dx.doi.org/10.5296/jet.v5i2.13021

\begin{abstract}
The paper investigates the training needs of workers in the fur industry and suggests the design of a respective training program. Based on the views of the workers themselves, the paper detects the theoretical knowledge and the practical skills necessary for their employment in this field as well as it identifies training gaps. In order to gain access to a big sample, the region of Macedonia, Greece was chosen as the place at which the field research took place, as it presents the highest numbers in fur production in the country. Qualitative field research, through semistructured interviews, has been conducted. The main findings of the survey showed that there is no training support for the fur industry in Greece, both at the level of initial education and at the level of continuous training of the employees in it. The workers' participation in a specialized training program will contribute to the upgrading of the industry, according to the workers' views.
\end{abstract}

Keywords: lifelong learning, training needs assessment, employees training, fur industry, craftsmen's training

\section{Introduction}

The aim of this research paper is to detect the training needs of fur workers and, more specifically, to detect the deficiencies in cognitive skills of as many workers as possible in the Greek fur industry, in order to form an effective vocational training program for the specific manufacturing and commercial sector (Karalis, 2005). Identifying the training needs of these employees was considered the first important step in shaping a training program that would meet the needs of fur professionals, help them keep track of changes in the industry and respond to modern challenges, such as the new characteristics of consumers and markets and the 


\section{Mll Macrothink}

Journal of Education and Training

ISSN 2330-9709

2018, Vol. 5, No. 2

technology-based production techniques (Draft proposal for inclusion in the Operational Program for the Western Region Macedonia 2014-2020). Thus, the research effort, based on the recording of the views of the professionals themselves, sought a holistic understanding of these needs as a prerequisite for the design of a training program that would satisfy them.

In this context, attempts were made to provide adequate answers to the following research questions:

a. To what extent do fur workers consider that they possess the theoretical knowledge and practical skills they need to work efficiently in this profession?

b. What shortcomings do furners have in terms of modern methods of practicing their profession?

c. What knowledge and skills should, in their view, be covered by a training program addressed to fur professionals?

The reason of conducting this research was the realization of the inadequate studies carried out so far - mainly in Greece - regarding the training needs of the fur workers.

This realization was particularly disappointing, given the enormous contribution of this industry both to the economy of the region, where fur professionals are active, and to the national economy. The need for exploring these needs through an extensive research in the region of Macedonia has arisen, since the fur profession, although part of the area's tradition, is in the middle of an acute crisis. This is due to both the international economic recession and the reluctance of the younger generation to be professionally occupied in this field. The lack of training that may render the fur field competitive might be a factor that contributes to this crisis.

\section{Literature Review}

According to Jarvis (1990), the term "learning" can be defined as follows: a) any permanent change in behavior due to experience; b) some relatively permanent change in behavior as a result of a habit or practice; c) the transformation of experiences, d) the process through which experience is converted into knowledge, and e) the memorization of information.

According to Vergidis $(2001 ; 2003 ; 2008)$, "Lifelong learning is an approach of all training activities (formal, non-formal and informal) of all levels, allowing them to be set up in an ongoing, continuous, interaction with the socio-economic, political and cultural reality. Lifelong learning is characterized by flexibility in time, space, content and teaching techniques."

The term "Continuing Education", which covers all learning opportunities, usually offered after the completion of compulsory education, is also relevant to the above term. These opportunities may cover either full-time or part-time work and include vocational or non-vocational training (Zarifis, 2014).

According to the Sector study by the Market Financial Analysis Unit of Pireaus Bank the single-dimensional orientation of the local economy is not at all favorable to the shift of interest towards the training of employees. In recent years, the Greek fur factory has made great efforts 


\section{Mll Macrothink}

to restore its international image. Therefore, the training of its employees is considered as indispensable. The Sector study has also found problems due to the aging of the workforce, the low attractiveness of the sector for young people, the lack of critical skills, and the loss of accumulated know-how. However, rebound in demand for fur products creates favorable prospects for the future of the industry.

According to the Feasibility Study entitled "Guidelines and Sectoral Investment Plan for Greek Furry" by the Hellenic Federation of Furs, there is the need for strengthening the Greek fur industry, through the development and implementation of a coordinated strategy for the promotion of the Greek fur factory. Particular attention was paid to the need for support of employees, the development of new jobs, as well as the training of specialized on artificial fur craftsmen. This study has also underlined the need for employee training.

According to the letter from the Kastoria Chamber to the President of the Hellenic Federation of Furnace on the "Proposal of the Kastoria Chamber for the Creation of a Pole of Competitiveness" (2014), three specialized programs have been proposed:

(a) Technology for the promotion and the advertizement of fur and leather garments

(b) Breeding, tanning and anti-pollution technology of the production units

(c) Technology for the design and production of fur and leather garments

According to Vogiatzis and the "Feasibility study for expanding the activities of "GOUNES KAMI SA" in the China market" (2011), among the strengths of the fur industry is the experienced and skilled staff. Significant weaknesses in the industry are: (a) the lack of diversification of fur garments; (b) the inability to adapt quickly to fashion changes and (c) the aging of the skilled workforce. The need for undertaking actions for lifelong learning and training as an opportunity for growth and expansion in major markets has been stressed. The uncontrolled and unrestrained development of fur farming constitutes a serious threat to the evolution of the fur industry.

Kalomenidou, Matthaiou and Bibika (2012) refer to downward trend in the fur productive sector due to the aging of the workforce and propose the creation of a school of the art of fur.

Aivanouli in her "The consequences of the economic crisis in the trade sector" (2012-2013) investigates the main reasons for the strong decline in the fur industry in our country in recent years. She concludes that the reasons lying under the decline are the low growth rate, the limited degree of exploitation of funding tools, the difficulty in adapting to current trends and market needs and the limited integration of new technologies in the industry.

The Western Macedonia Region Draft Proposal for the Development of the National Development Strategy Guidelines (2014-2020) refers to the insufficiently trained workforce, the severe inability to link research to practice, the worrying weakness in access to and use of information and communication technologies. The proposal stresses the need for strengthening the linkage between education and research centers with enterprises and for developing the right conditions and climate for utilizing the endogenous workforce.

According to Triantafyllou (2006), the fur industry in the region of Siatista and Kastoria maintains the traditional way of processing the fur. The specific study also states that 


\section{Macrothink}

specializations in the industry are usually overlapping in terms of human resources.

According to Mimis (2007) an upgrading of the skills of the human capital of the Prefecture of Kozani has been observed, which, however, coexists with the trend of human resources with high educational level leaving the area and the industry. Therefore, there is the need for policy design and implementation of continuing training actions.

Giannakopoulou (2012) refers to the new specialties of craftsmen and new operators of production process which makes necessary the employment of specialists on leather and fabric the continuous training of old and new designers.

Finally, a China Survey (2010) has shown that there is no organized training system for fur breeders, breeding farms are of a family nature and technological equipment is seldom used.

\section{Methodology}

The purpose of the survey is to identify and thoroughly investigate the training needs of fur workers. The specific objectives of the research are to record these needs, to process them and to distinguish them from theory and practice. The results from this processing are expected to be a useful source of information for designing and implementing a successful training program for those aspiring to work professionally with this industry and those already employed in it.

In particular, the paper seeks to provide complete and clear answers to the following research questions:

a. To what extent do fur workers consider that they possess the theoretical knowledge and practical skills they need to work efficiently in the profession in question?

b. What shortcomings do furners face in terms of modern methods of practicing their profession? c. What knowledge and skills should, in their opinion, be covered by a training program aimed at fur professionals.

The survey sample consists of 8 people, including seven men and one woman. Six of them belong to the age group of 40-50, one in the age group of 20-30 and one in the 30-40 age group. Also, two of them have a Lyceum Certificate, four have been through compulsory education and two of them hold a University or Technological Institute degree. One of the participants is unemployed, three are self-employed and four are employees in the private sector. Finally, it is noted that a person is a female office worker, four are furriers, a fur farmer and two fur garbage dealers. This sample is considered to be sufficient and capable of providing safe conclusions, as it is employed in the fur field and is characterized by satisfactory dispersal in the fur industry.

In order to collect and process the required data, the qualitative field research was considered the most appropriate method (Creswell, 2011). The choice of this method was based on the pursuit of a holistic understanding of the subject rather than a simple description of it. In addition, it offers a comparative advantage, as it explores the experience of social subjects, and in the case of the present study, of the workers in the fur industry. It should also be noted that the in-depth investigation and recording of the needs of the industry was preferred, since, in fact, no corresponding research efforts have been made in the past (Creswell, 2011).

Its basic tool will be the semi-structured interview (Iosifidis, 2008) with industry professionals, 


\section{Mll Macrothink}

who will be asked to answer predefined questions, having though at the same time the possibility of a free discussion with the interviewer.

\section{Findings}

On the first pillar of questions, the respondents answered questions about the extent to which they feel they possess the necessary knowledge and skills to work in the fur industry. More specifically, in the question about the knowledge and skills required in the fur industry, all respondents agreed that they need specialized knowledge and skills for such work. In addition to this knowledge, the need for knowledge of the market, trade and exports, as well as knowledge of business administration, accounting, economic principles, foreign languages and sales techniques was highlighted. In addition, six out of eight participants stressed the need for knowledge of the fur processing stages, from fur farming to the sale of finished fur garments and products.

Next, in the question about the type of training received by respondents in order to work professionally in the fur industry, the majority responded that they have received practical training by being apprenticed next to older and experienced craftsmen. These replies emphasized that this art is transferred from the older to the younger generation to family or friends-furriers. Finally, in one of the replies it was reported that fur industry related subjects are not taught at any educational level, while in two others reference was made to the need for specialized marketing and business management skills and a university degree respectively.

Most of the participants agreed with the view that the fur industry could be the subject of academic studies. Some argued that this could be done even at secondary and post-secondary level. One of them pointed out the difficulty of such an effort, citing the necessary presence of specialized teachers and expensive raw materials for the practical training of the students, while another mentioned the difficulty of integrating all subjects of the industry into a single subject of academic studies. Moreover, the absence of training support for this sector, which was attributed to its concentration only in Siatista and Kozani in Greece, as well as the huge gap in the training of craftsmen, was highlighted. Finally, one of the respondents was concerned about the drop in the number of new craftsmen, which, he said, could cause a major problem in the future.

The second pillar of questions included questions about the lack of training on modern methods of practicing the profession. More specifically, with regard to the Greek furnace training programs, all respondents referred to the minimal programs that are occasionally organized by the Vocational Training Centers and Fellow Associations as well as by the OAED (The Hellenic Organization for the Occupation of the Unemployed) Furry School.

In the question of how they use new technologies to practise their profession, participants have unequivocally replied that no modern methods are used in the production and manufacture of fur products. Indeed, three of them stressed that the art of fur is purely manual, so new technologies are not needed. Modern methods are used in the trade of fur and, in particular, in marketing and management, as well as in the computerization of a furry business, requiring the use of modern software. 


\section{Mll Macrothink}

Deficiencies in the use of new technologies in this profession have been identified not so much in the production as in the trade, exports and sales. Half of the respondents replied that new technologies are needed to promote sales, while two of them focused on the need for use of social media. On the other hand, a respondent identified shortcomings in statistical data and behavioral studies as well as shortcomings in training structures and lifelong learning structures. Finally, the office worker of a furnace company did not find any deficiencies in the use of new technologies in the field.

In the third pillar of the questions, the participants focused on the knowledge and skills that a training program for fur professionals should provide. In particular, regarding the kind of knowledge that such a program could offer, several of them replied that these programs should approach both the production and the promotion of fur. It was argued that this knowledge needs to be specialized and to cover the whole range from the production of the fur to the production of the finished product. Moreover, emphasis should be put on the promotion of the products in the domestic and international market. In addition, the need for organized and specialized training programs for fur worker trainers, fur workers, fur traders, managers and salespeople was highlighted.

By focusing the attention of the participants on the orientation of fur training, the answers given were mostly in favor of the practical orientation. In particular, six out of eight have emphasized that training in the fur industry needs to follow a practical approach. The other two participants distinguished the type of orientation according to the specialty: for practitioners' practical orientation and for the other specialties, such as the management of a furnace enterprise, both theoretical and practical.

The question as to how to integrate new technologies into a training program for fur professionals, one participant referred to training on a one-to-one basis, while the other seven talked about basic computer skills depending on the professional's specialization. They insisted on the use of e-commerce and social media, while the inclusion of software and CAD programs was reported in various procedures, such as the computerized warehouse for ready-made fur.

Finally, all respondents felt that their participation in a fur training program would help them to work more effectively in their profession. More specifically, one of them expressed the view that modernization of enterprises through the upgrading of their human resources is a key driver of their competitiveness. Furthermore, most participants noted that this would fill in the gaps in terms of the knowledge and skills that were transferred to them mainly empirically. Some have emphasized that they will acquire knowledge that they cannot acquire any other way. It also talked about employee development and improved efficiency through the use of modern tools. Another respondent insisted on the need for lifelong learning and monitoring of modern furnace developments and stressed the need for protection and upgrading of the particular profession through the development of its existing human resources and the development of a new pool of specialized employees.

\section{Discussion of the Results}

As a result of the survey, training of fur workers is informal in the sense that it takes place 


\section{Mll Macrothink}

Journal of Education and Training

ISSN 2330-9709

2018, Vol. 5, No. 2

through interaction with their immediate professional environment and not within a formal established training system, which can justify a significant proportion of their training needs. Given that it was argued that their subject could be the subject of academic studies at secondary and post-secondary level, this confirms their desire to receive formal education on their field. In addition, it was clearly reflected that their continued professional training would help them evolve and follow the latest trends in their field, through linking lifelong learning to the professional development of the individual.

Concerned about the absence of training programs in the fur industry in our country, an absence that does not seem to be in line with European policies on lifelong learning, and which substantiates the dominance of the anachronistic statist lifelong learning model, is worrying. The lack of continuing vocational training programs can be attributed to the fact that this sector is booming in a particular geographic area of the country (Western Macedonia), therefore it does not attract the interest of the state institutions. It can also be attributed to the fact that it is a traditional manual art, passed from one generation to the next, and therefore does not require training support.

An unpleasant finding of the research was the absence of training programs for fur professionals, at least on a regular and organized basis. The occasional character of some programs, obviously of a seminar type, does not seem to cover their training needs, a fact which they themselves highlighted in their responses. Thus, we cannot talk about designing a formal curriculum, with specific stages or explore the training needs of fur workers, although these needs are real and can be defined in the context of the specialization of workers and the required knowledge, skills for the system of distribution, use, maintenance and repair of the products produced.

The answers that emerged showed that these needs were latent and non-explicit, as the respondents were unable to identify them precisely and clearly. Probably, their lack of formal education is responsible for this, but this cannot be assured with certainty. What can be assured with certainty is that these needs are not only for individuals but for specific target population (fur workers) as well as for the geographic unit of Western Macedonia and its economic activity furs. The process of investigating them is non-existent due to the general lack of training support for the industry.

Furthermore, the above findings confirm, in general, what emerged from the review of previous literature. More specifically, the traditional character of furry art was also found in 2006 by Triantafyllou. At the same time, the need to train fur workers - and especially fur craftsmen was also revealed in the Piraeus Bank Manufacturing Market Sector Analysis Study and in the Feasibility Study entitled "Guidelines and Sectoral Investment Plan for the Greek Furnace" by the Hellenic Federation of Furs. In addition, the importance of lifelong learning and training in the fur industry, which was noted in the "Feasibility Study on the expansion of the activities of "GOUNES KAMI SA" in the market of China" in Vogiatzis (2011), in Mimi's research (2007) but also in Giannakopoulos' study (2012), is a major finding of this research. Regarding the use of new technologies in the studied field, the findings of the research in China (2010) about its scarcity were confirmed, as well as the conclusion of the Western Macedonia Region's Draft 
Proposal for the development of the National Development Strategy Guidelines 2014-2020.

Regarding the use of new technologies in the studied field, the findings of the research in China (2010) about its scarcity were confirmed, as well as the conclusion of the Western Macedonia Region's Draft Proposal for the development of the National Development Strategy Guidelines 2014-2020, regarding the (a) technology for the promotion of fur and leather garments; (b) the breeding, tanning and anti-pollution technology for the production units and (c) furnace and leather garment design and Production Technology, as formulated in 2014 in the Letter from the Kastoria Chamber to the President of the Hellenic Federation of Furnace on the "Proposal of the Kastoria Chamber for the Creation of a Pole of Competitiveness".

By continuing to interpret the findings, we find that they confirm the research questions of this research. In particular, with regard to the degree to which Greek fur workers themselves hold the necessary theoretical and practical skills for their efficient occupation in this sector, it has emerged that their knowledge - except for a few exceptions - is empirical in character and is not product of academic studies. This is mainly reflected by their answers to the question of the type of training they have received to work in the field, which, combined with their positive response to the question of whether their industry could be the subject of academic studies, leads us to the conclusion that they recognize that their knowledge is incomplete and that it should be enriched through education.

On the other hand, regarding the shortcomings, they believe they exist, in terms of modern methods of practicing their profession, the lack of furnace training programs has been clearly stated. The occasional nature of these programs proves that the training of workers in this sector is being treated with frivolity and without a defined framework and planning. Though many have said that modern methods are not needed in the production of fur, they admitted that computer knowledge would be very useful in the field of trade, exports, marketing and management. Particular reference has been made to e-commerce and social media, which proves workers' skills shortages in new technologies.

Finally, regarding the knowledge and skills that a training program for fur professionals should provide, it seemed clear that employee shortages are both theoretical and practical, depending on their specialty. Thus, craftsmen believe that a training program should have a practical orientation, while traders are in favor of a combination of theoretical and practical orientation. Regardless of orientation, however, everyone agreed that new technologies could be integrated into this program, which shows their shortcomings in their use. Everyone also indicated that their participation in such a program would help them to perform their profession more effectively because they would provide them with knowledge they could not otherwise acquire because of the lack of fur training. At the same time, it would enable them to fill in the gaps in their empirical knowledge, which substantiates the need for training support for this industry.

\section{Limitations of present study and suggestions for future research}

The research carried out has been inherently restricted due to the lack of literature on its subject, its limited space and time, and the incomplete knowledge of the participants on this topic. At the same time, the research process faced difficulties, due to the laxity of the answers given, as 


\section{Macrothink

well as the fact that several of them did not answer directly and clearly to the question that had been asked. The transfer of the fur art from generation to generation to small family businesses has had a decisive impact on the mentality of the respondents, whose answers have been steadily oriented towards the traditional character of the fur industry. Future research could focus on a larger sample and take the form of a survey through quantitative research in order to find out more about the industry trends and needs.

\section{Conclusions}

The research carried out has led to useful conclusions regarding both initial education and the lifelong learning of fur professionals. Its contribution is of adding value since there has been no corresponding research effort on this issue to date. On the other hand, one should not neglect its basic conclusion, which is related to the lack of educational and training support for this sector, whether it is seen from the point of initial education of its employees or from the side of their training.

Existing knowledge on the training needs of fur professionals could only be characterized as non-existent, as can be seen from the review of not only domestic but also international literature.

Investigations by official bodies are minimal and do not focus on the specific issue. Thus, this research provides basic knowledge about the training needs of fur workers, highlighting that these needs exist, are mainly linked to the use of new technologies and are sufficient to substantiate the argument of designing and implementing an organized training effort.

\section{References}

Aivanouli, E. (2012-2013). The impact of the economic crisis in the field of commerce [Ol

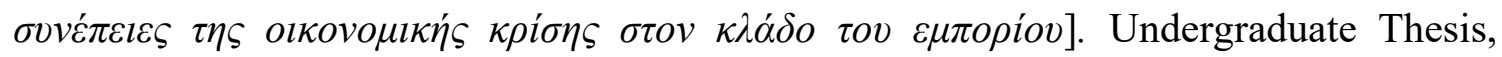
School of Business Administration and Economics, Alexandreio Technological Institute of Thessaloniki.

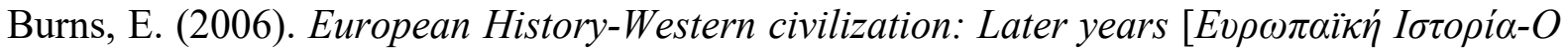

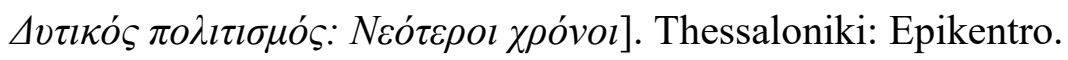

Chamber of Kastoria. (2014). Letter to the Hellenic Federation of Furnace on "The proposal of Kastoria Chamber for the creation of a pole of competitiveness". Kastoria: Chamber of Kastoria

Creswell, W. J. (2011). Design, Implementation and Assessment of Quantitative and

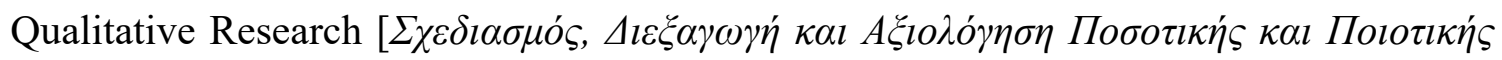

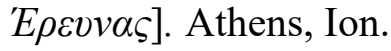

Giannakopoulou, G. (2012). Mink farming in Northern Greece for fur production - Possibilities

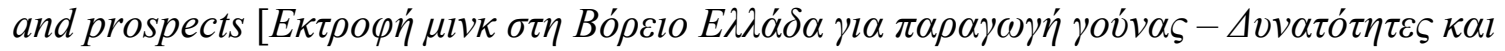

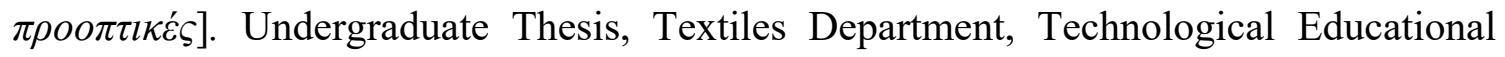
Institute of Piraeus, School of Technology Applications. 


\section{Macrothink

Green, A. (2003). The multiple facets of life-long learning: Modern trends in educational

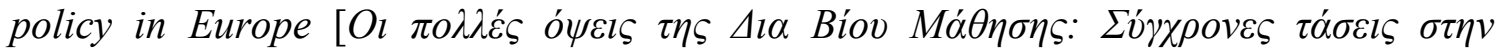
$\varepsilon \kappa \pi \alpha \iota \delta \varepsilon v \tau \imath \kappa \eta \dot{~} \pi о \lambda \imath \tau \imath \kappa \eta ́ ~ \sigma \tau \eta v ~ E v \rho \omega ́ \pi \eta]$. Announcement in Conference entitled Professionalism in Continuous Learning, University of Macedonia, 16-17 May.

Hellenic Federation of Fur. (2009). Study of Intentions: Directional, Sectorial Investment Plan

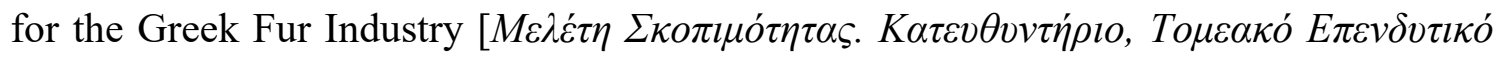

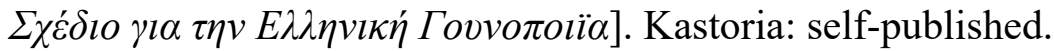

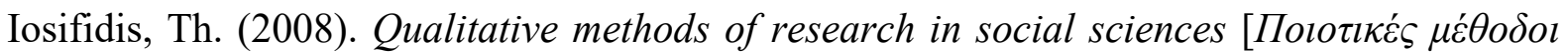

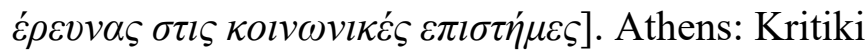

Jarvis, P. (1990). International Dictionary of Adult and Continuing Education. London: Routledge

Kalomenidou, Ch., Mattheou, Ch., \& Bibika, M. (2012). Farm Management and Fur

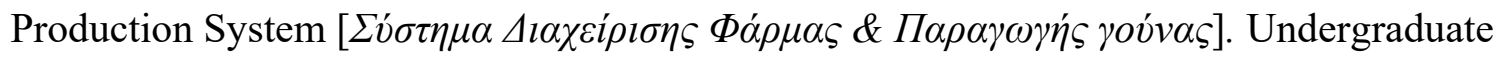
Thesis, Department of Industrial Production, Technological Institution of Kavala.

Karalis, Th. (2005). Design of Programs [ $\Sigma \chi \varepsilon \delta \imath \alpha \sigma \mu o ́ \varsigma ~ \Pi \rho o \gamma \rho \alpha \mu \mu \alpha ́ \tau \omega \nu] . ~ v o l . ~ B '$, Patra: Hellenic Open University

Mimis, D. (2007). Strategic Plan for the Development of the Prefecture of Kozani. From

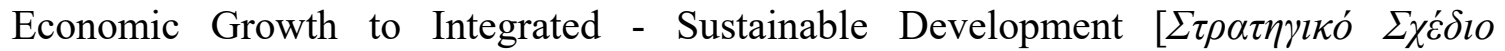

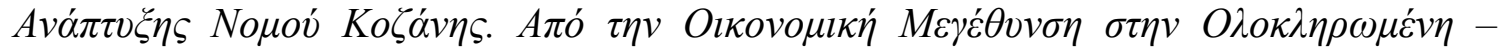

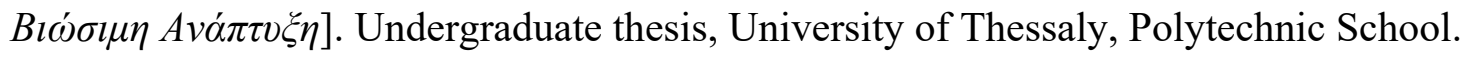

Pireaus Bank- Market Financial Analysis Unit. (2012). Sector Study 17.Fur Industry, Athens: Pireaus Bank.

Triantafyllou, A. (2006). The effects of 'monocracy' on organizing the productive system of a

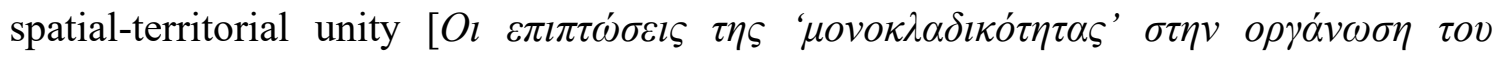

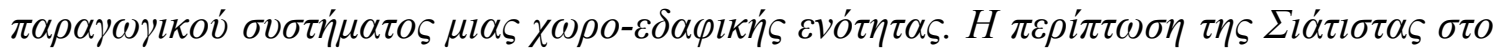

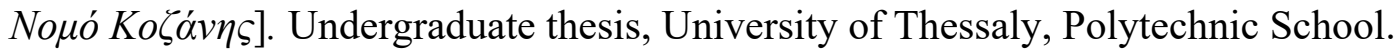

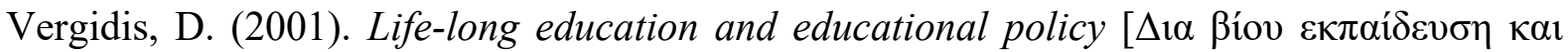

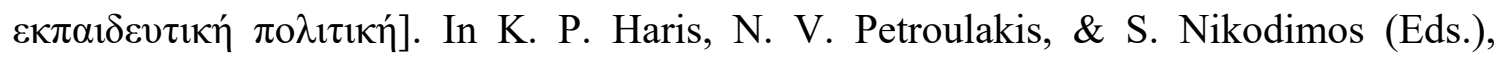

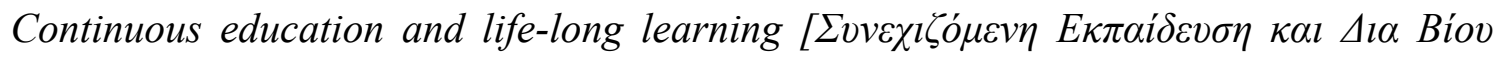
Mó $\theta \eta \sigma \eta]$ (pp. 127-144). Athens: Atrapos,

Vergidis, D. (2003). The design of adult education programs for vulnerable social groups

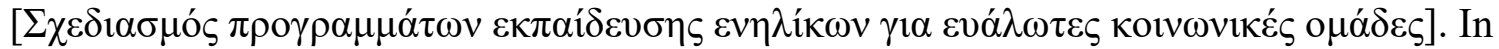
D. Vergidis, Adult Education: Contribution to the specilisation of executives and trainers

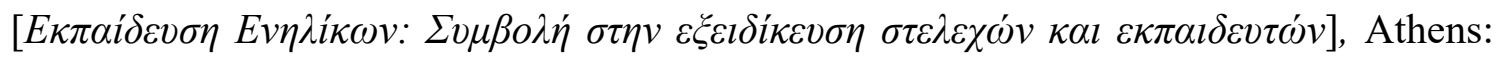
Ellinika Grammata.

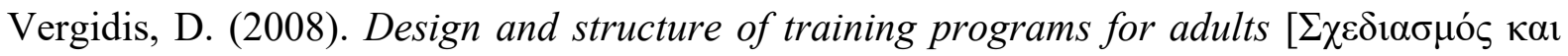

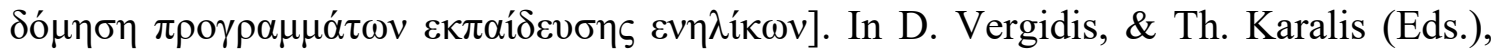




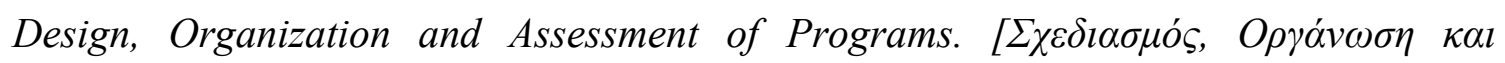

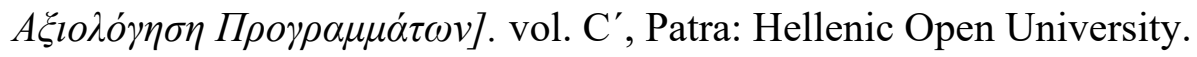

Vogiatzi, E. (2011). Study of intentions for expanding the activities of "GOUNES KAMI SA"

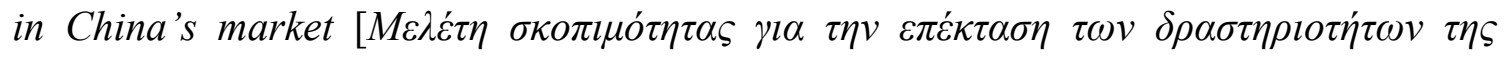

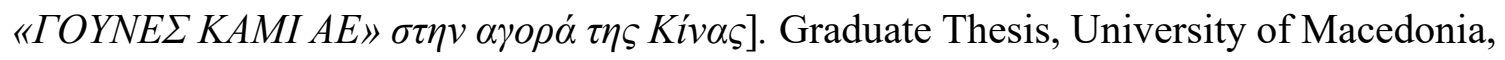
Greece, Inter-departmental Postgraduate Program in Business Administration.

Zarifis, G. K. (2014). Continuous education and life-long learning: Theory and Practice

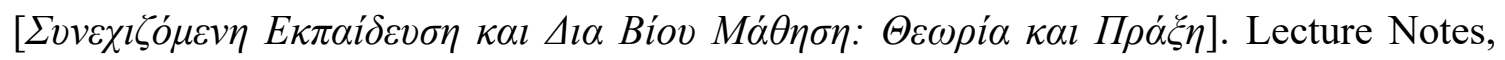
Thessaloniki: Aristotelion University.

\section{Copyright Disclaimer}

Copyright reserved by the author(s).

This article is an open-access article distributed under the terms and conditions of the Creative Commons Attribution license (http://creativecommons.org/licenses/by/3.0/). 